\title{
The Mid-Lithospheric Discontinuity caused by channel flow in the cratonic lithosphere
}

Haibin Yang ${ }^{* a, b}$, Irina M. Artemieva ${ }^{c, d, e}$, Hans Thybo e,f,g

a. School of Earth Sciences, University of Melbourne, Melbourne, Australia

b. Research School of Earth Sciences, Australian National University, Canberra, Australia

c. Department of Geophysics, Stanford University, Stanford, CA 94305, USA

d. Section of Oceanic Dynamics, GEOMAR Helmholtz Center for Ocean Research, Kiel 24148, Germany

e. State Key Laboratory of Geological Processes and Mineral Resources, School of Earth Sciences, China University of Geosciences, Wuhan, China

f. Eurasia Institute of Earth Science, Istanbul Technical University, Maslak, 34469 Istanbul, Turkey

g. Centre for Earth Evolution and Dynamics (CEED), University of Oslo, Blindern, 0316 Oslo, Norway

Corresponding author: Haibin Yang

Email: haibin.yang@anu.edu.au

This is a non-peer reviewed preprint submitted to EarthArXiv. 


\section{Abstract}

Stable cratons with a thick (> $200 \mathrm{~km}$ ) and cold lithosphere form rheologically strong plates that move atop a ductile asthenospheric mantle. Various types of seismic observations show the presence of a potentially rheologically weak zone at depths of ca. $80-150 \mathrm{~km}$ termed the Mid-Lithosphere Discontinuity (MLD). While various mechanisms may explain the MLD, the dynamic processes leading to the seismic observations are unclear. We propose that the MLD can be caused by channel flow in the lower lithosphere, triggered by negative Rayleigh-Taylor instabilities at cratonic margins in the Archean, when the mantle was hotter than at present. Presence of a chemically distinct, low-density cratonic lithospheric root is required to initiate the process. Numerical modeling shows that the top of the channel flow creates a shear zone at a depth comparable to the globally observed seismic MLD. Grain size reduction in the shear zone and accumulation of percolated melts or fluids along the channel top may reduce seismic wave speeds as observed in the MLD, while the channel flow itself may explain radial anisotropy of seismic wave speeds. Secular cooling of the Earth deepens the top of the channel flow on a 1 Gyr scale, and early-stage large-scale (1000's km long) channel flow deformation switches to a different deformation style with a smaller (100's km) wavelength. These different flow patterns may explain the different seismic response of the MLD and the lithosphere base.

Keywords: Mid-Lithospheric Discontinuity; Low velocity zone; Lithospheric mantle; Seismic anisotropy; Radioactive heat. 


\section{Introduction}

The plate tectonic model requires that the outermost layer of the solid earth, the lithosphere, moves as rigid plates on a weak viscous zone, often referred to as the asthenosphere. The depth to the lithosphere-asthenosphere boundary (LAB) in stable cratons is debated and is typically interpreted at depths between ca. 200 and $400 \mathrm{~km}$, as estimated from heat-flow analysis (Artemieva and Mooney, 2001), mantle xenoliths

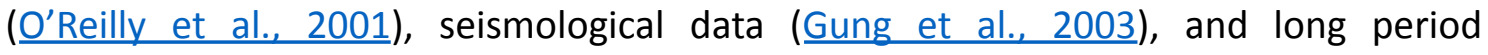
magnetotelluric data (Jones et al., 2003). Conversely, high-resolution seismological data reveal a complex structure of the mechanically strong layer (Fig. S1).

Extensive high-density, long-range seismic sections detected intra-lithosphere discontinuities at depths around $90-130 \mathrm{~km}$ in the Baltic Shield (Perchuc and Thybo, 1996) and later globally under stable continents (Thybo and Perchuć, 1997) (Fig. S1). These seismic discontinuities mark the top of a seismic low-velocity zone with a small reduction in P-wave velocity $(\mathrm{Vp})$ and a larger reduction, of up-to 6\%, in shear wave velocity (Vs) over a depth range of $20-50 \mathrm{~km}$ in the Baltic Shield (Abramovitz et al., 2002). Similarly, the presence of one or multiple seismic low-velocity zones with the top typically at depths of ca. $80-100 \mathrm{~km}$ and a thickness of $20-40 \mathrm{~km}$ were reported for the Siberian Craton based on the Soviet PNE long-range profiles (Egorkin et al., 1987). Beneath the North American craton, joint inversion of the high frequency $\mathrm{P}$ wave coda with long period surface wave dispersion data identified not only a velocity discontinuity with a $2.1 \%$ Vs decrease at depths of ca. $100-120 \mathrm{~km}$ beneath the cratonic stations, but also a positive intra-lithospheric discontinuity at around $150-170 \mathrm{~km}$ depth with a 3.6\% Vs increase (Calo et al., 2016). 
The intra-lithosphere seismic discontinuity with a negative velocity converter at depths ca. $70-120 \mathrm{~km}$ globally under stable continents has also been identified by high-frequency seismic receiver function (RF) studies (Rychert and Shearer, 2009). Similar studies, largely based on S-RF (S-wave receiver functions), reported a negative converter at ca. $60-85 \mathrm{~km}$ depth beneath the Precambrian Western Australia_Sun et al., 2018) and typically at ca. 80-120 km depth beneath the cratonic North America (Chen et al., 2018). Beneath the Kalahari craton, some S-RF studies identified a shallow (80-90 km depth) negative converter found in other S-RF studies (ychert and Shearer, 2009), while other S-RF studies found a prominent interface with a $4.5 \%$ reduction in seismic velocity at ca. 150-160 km depth (Savage and Silver, 2008). Notably, the deep converter corresponds to the top of melt-metasomatised mantle beneath the Kaapvaal craton (Griffin et al., 2003) (Fig. S1b).

Vertical stratification of the cratonic lithosphere with the transition between compositionally distinct layers at ca. $120-150 \mathrm{~km}$ depth is revealed by mantle xenolith studies in the Archean-Paleoproterozoic provinces of the Slave craton and the Baltic Shield (Kopylova and Caro, 2004). Vertical stratification of the cratonic lithospheric mantle is also imaged in seismic azimuthal anisotropy studies of the North American and the Australian cratons, which show a boundary between mantle layers with different fast directions at ca. 100-150 km depth (Yuan and Romanowicz, 2010; Sun et al., 2018). Likewise, strong electrical anisotropy has been reported for the Superior Province of the North American craton with the top of the anisotropic layer at ca. 70-100 km depth (Mareschal et al., 1995), while in the Slave craton a pronounced decrease in electrical conductivity by 0.5 log unit at $135-150 \mathrm{~km}$ depth (Jones et al., 
2003) closely correlates with the compositional boundary established from mantle xenoliths (Kopylova and Russell, 2000).

This brief overview demonstrates the presence of an intra-lithosphere heterogeneity at a depth of around $100 \mathrm{~km}$ in stable continental lithosphere globally, although with significant regional depth variations (Fig. S1). It is, however, still debated if the top of an intra-lithospheric seismic refraction low-velocity zone and negative seismic convertors imaged by RFs (later referred to as the Mid-Lithospheric Discontinuity, MLD) image the same intra-lithospheric transition zone, and if anisotropic layering and metasomatic imprint on composition of the cratonic lithospheric mantle correspond to the same feature. Various models have been brought forward to explain the MLD, such as: (i) rheological layering at temperature close to the solidus in the presence of melt/fluids (Thybo and Perchuć, 1997; Thybo, 2006), (ii) compositional layering due to either partial melt extraction (Yuan and Romanowicz, 2010), or basaltic melt additions and metasomatism associated with magmatic activity (Thybo, 2006; Rader et al., 2015), (iii) change in deformation style, either depth-dependent (Karato et al., 2015), or time-dependent such as transition from frozen-in (e.g., associated with mineral fabric inherited from cratonization) to young seismic anisotropy (Yuan and Romanowicz, 2010).

These mechanisms are under discussion. Firstly, it is debated if solidus temperature may be reached at mid-lithosphere depths below stable continents even for a fertile and volatile-rich composition (Karato et al., 2015). Secondly, compositional layering may not necessarily relate to the seismic MLD. Minerals rich in carbon or amphibole may produce a $>5 \%$ seismic wave velocity drop ( Selway et al., 2015), but 
mantle xenoliths suggest that such minerals may not occur ubiquitously in cratonic lithosphere (Rader et al., 2015; Selway et al., 2015). Thirdly, an analysis of feasible mechanisms for a seismic velocity change in seismic S-wave receiver function suggests that radial anisotropy in seismic wave velocity could be a strong candidate to explain the seismic MLD (Selway et al., 2015). However, this model requires a global operation of a geological process which produces the same anisotropic layering pattern at the same depth range in every craton, and such process is yet unknown. Azimuthal anisotropy may either increase or decrease seismic wave velocity depending on the back azimuth of the seismic waves, but this is not revealed by long-range seismic controlled-source profiles in the cratons of North America, Siberia and Baltica (Thybo, 2006). An elastically accommodated grain-boundary sliding and mantle hydration, e.g. by melt metasomatism, seem to predict a velocity drop similar to observed at the MLD (Karato et al., 2015). However, the model indicates no relationship between a reduction in seismic wave velocity at the MLD and anisotropy variations within the lithospheric mantle. Therefore, mechanisms for the presence of the MLD should explain the following features: (1) a seismic velocity interface observed both in seismic controlled-source and RF models, (2) a transition between layers with different directions of seismic, and possibly electrical, anisotropy, (3) depth variations of the intra-lithosphere discontinuity in various cratons.

Here, we propose a new mechanism that may resolve the controversy. It allows for the formation of a rheologically weak mid-lithosphere zone in the cratons globally, with the associated changes in seismic velocity and formation of anisotropic layering. We propose that a global mid-lithosphere weakness zone may have formed in the 
Precambrian at the early stages of cratonization by channel flow in the mantle. We argue that the intensity of the channel flow mechanism gradually ceased with time due to secular cooling of the Earth's interior. We test the model predictions by a 2D thermomechanical numerical modeling. Our numerical results, coupled with observations of seismic-wave anisotropy and petrological studies in various cratons, may reshape our understanding of the evolution, longevity and stability of cratonic lithosphere.

\section{Method}

\subsection{Governing equations}

A new 2D finite difference code LYSI is used in our numerical experiments (Yang et al., 2018). The code applies a marker-and-cell technique to solve thermo-mechanically coupled conservation equations of mass, momentum:

$$
\begin{gathered}
\nabla \cdot u=0 \\
\nabla \cdot \sigma^{\prime}-\nabla P+\rho g=0
\end{gathered}
$$

where $u$ is velocity, $\sigma$ is deviatoric stress, $P$ is dynamic pressure, $\rho$ is density and $g$ is gravitational acceleration. For the equation of conservation of mass (1), we assume an incompressibility condition. To reflect changes in temperature, we solve heat conservation equation

$$
\rho c_{p}\left(\frac{\partial T}{\partial t}+u \cdot \nabla T\right)-\nabla \cdot k \nabla T-H=0
$$

where $c_{p}$ is heat capacity, $k$ is thermal conductivity and $H$ is heat production (only radioactive heat source is considered). 


\subsection{Rheology.}

The visco-plastic non-Newtonian rheology automatically adjusts to physical conditions. For ductile deformation, the flow law can be formulated as:

$$
\dot{\varepsilon}=A(\sigma)^{\prime n} \exp \exp \left(-\frac{E+V P}{R T}\right)
$$

Where $\varepsilon$ is strain rate, $A$ is material constant, $n$ is stress exponent, $E$ is activation energy, $V$ is activation volume, and $R$ is gas constant. Wet quartzite, Anorthosite and Olivine are proxies for the rheology of the upper crust, lower crust and mantle in this study, respectively. With equation (4), we can reformulate it to obtain the effective viscosity

$$
\eta=\frac{\sigma}{2 \dot{\varepsilon}}
$$

A maximum model cut-off effective viscosity is set up to $10^{25} \mathrm{~Pa} \cdot \mathrm{s}$ and $10^{18} \mathrm{~Pa} \cdot \mathrm{s}$ for minimum viscosity. When stress reaches a threshold value changing flow law from viscoelastic to plastic failure, we use Drucker-Prager yield criterion,

$$
\sigma_{\text {yield }}=P \tan \tan \phi+C
$$

where $\sigma_{\text {yield }}$ is the square root of the maximum second deviatoric stress invariant, $P$ is pressure, $\tan \tan \phi$ is friction coefficient and $C$ is cohesion. Details about parameters used in numerical experiments are listed in Table S1.

\subsection{Time-dependent radioactive heat generation rate}

To investigate the effect of radioactive heat generation we have implanted the time dependent heat generation model based on a three-dimensional global reference model (Huang et al., 2013) (Table S2). Heat generated by radioactive elements in earth 
interior

can

be

expressed

by

(Rybach,

1976):

$H=0.01 \rho\left(9.52 C_{U}+2.56 C_{T h}+3.48 C_{K}\right)$, where $H$ is heat production per unit volume $\left(\mu W / m^{3}\right), C_{U}$ and $C_{T h}$ are concentrations of isotopes $U$ and $T h(p p m), C_{K}$ concentrations of $K(w t . \%)$, and $\rho$ is density $\left(\mathrm{g} / \mathrm{cm}^{3}\right)$. The history of radioactive heat generation can be formulated as $N_{t}=N_{0} e^{\frac{t}{\tau}}$, where $N_{t}$ is historical concentration of the radioactive element, $N_{0}$ is current concentration, and $\tau$ is the mean lifetime, which can be calculated with half-life $\left(t_{\frac{1}{2}}\right): \tau=\frac{t_{\frac{1}{2}}}{\ln 2}$. The half-life for U235, Th232 and K40 are 0.704 Ga, 14.01 Ga, and 1.25 Ga, respectively (Dickin and Halliday, 1995).

\subsection{Model setup}

\subsubsection{GEOMETRY}

The model domain is a rectangular box with a dimension of $4000 \mathrm{~km} \times 600 \mathrm{~km}$, resolved on $401 \times 121$ grid nodes (Fig. 1a), with free slip at all four boundaries. The model includes four layers. The free surface deformation is designed by a 'sticky air' layer 1 (20 km thick) overlying a 40-km-thick crust (layer 2) above the lithospheric (layer 3) and sub-lithospheric mantle (layer 4). The density of the depleted shallow cratonic lithospheric mantle is assumed to be $20 \mathrm{~kg} \mathrm{~m}^{-3}$ less than of the sublithospheric mantle (Carlson et al., 2005). The compositional discontinuity between the lithospheric and sublithospheric mantle is referred to as the chemical LAB (CLAB). At time zero of the model evolution, the chemical lithospheric mantle has a thickness of $195 \mathrm{~km}$ in the cratonic part of the model (model distance $x=0-2400 \mathrm{~km}$ ) and $95 \mathrm{~km}$ in the 
non-cratonic part $(x=2600-4000 \mathrm{~km})$, with a linear change in the CLAB depth in a 200-km-wide transition zone between the two domains.

\subsubsection{Chemical and thermal boundary LAYers}

Time zero corresponds to the Precambrian formation of a compositionally low-density continental lithosphere root (the chemical boundary layer, $\mathrm{CBL}$ ) made of buoyant material left behind after extensive melt extraction from the mantle (Carlson et al., 2005). Therefore, CLAB (which marks the base of the CBL) is initially deeper than TLAB (the thermal LAB), which is the bottom of the conductive thermal boundary layer, TBL (Fig. 1b), and our model setup at time zero differs from a xenolith-constrained model for cratonic lithosphere with $C B L<T B L$ based on the presence of fertile peridotites in the lower portion of the lithospheric mantle (Lee et al., 2005). In our interpretation, this feature develops during cratonic evolution through continuous interaction between mantle convection and the lithospheric root which leads to metasomatic modification of its lower portion.

At the start of cratonic evolution in the Archean (time zero), high concentration of radioactive elements in the chemical lithosphere (Fig. 1d) and high Archean geothermal gradient ( $\underline{\text { Herzberg et al., 2010) }}$ cause partial melting of lower lithospheric mantle above the CLAB, therefore creating a large (45 to $145 \mathrm{~km}$ ) vertical offset between TLAB and CLAB (with zTLAB < zCLAB) (Fig. 1ab). The molten lower part of the Archean $C B L$ (i.e., the layer between the TLAB and the CLAB) with lower viscosity than in the upper, conductive, layer of the lithospheric mantle can form a secondary convection system within the lithosphere root, which is separated from the convection in the sublithospheric mantle (Sleep, 2003). This layered structure of the convecting 
upper mantle may produce complex geotherms. We simplify the geotherm shape by (i) assuming a continuous adiabatic gradient of $0.3^{\circ} \mathrm{C} \mathrm{km}^{-1}$ in all convecting mantle layers and (ii) initially placing the TLAB at $90 \mathrm{~km}$ depth (Herzberg et al., 2010). Over time, the secular cooling of the mantle gradually deepens the TLAB, while preserving the CLAB depth largely unchanged.

\subsubsection{Mantle temperatures}

The initial mantle potential temperature is assumed to be $1500{ }^{\circ} \mathrm{C}$ (Fig. $1 \mathrm{~b}$ ), which is ca. $200{ }^{\circ} \mathrm{C}$ higher than at present, in accordance with geochemical models on mantle melting temperatures in the Archean (Nisbet et al., 1993). To reflect the long-term cooling of the Earth, we introduce a time-dependent heat generation decay based on a three-dimensional global reference model for the crust and upper mantle (Huang et al., 2013) (Fig. 1c,d; see Supplementary Table2). For a high rate of radioactive heat generation in the Archean lithosphere, a $200{ }^{\circ} \mathrm{C}$ lithosphere temperature anomaly converges to a cratonic geotherm after $1 \mathrm{Gyr}$ (Michaut and Jaupart, 2007).

\section{Results}

\subsection{General pattern}

During model evolution, the difference in radiogenic heat production across the CLAB (with a higher heat production in lithospheric than asthenospheric mantle (Huang et al., 2013) enhances the existing lateral density contrast across the craton-to-noncraton transition (with a $100 \mathrm{~km}$ vertical offset in CLAB at around $\mathrm{x}=$ $2400-2600 \mathrm{~km}$ ). It facilitates the development of Rayleigh-Taylor instabilities in the 
sublithospheric mantle adjacent to craton edges, leading to a descent of cold and dense material of shallow sublithospheric mantle into hotter and less dense deeper mantle. The downward movement of shallow asthenosphere material reduces the dynamic pressure around the craton edge with respect to pressure in cratonic chemical lithosphere far from the craton edge ( $x<1500-2200 \mathrm{~km}$ ) (Fig. 2a). As a result, the horizontal pressure gradient in the lower chemical lithosphere creates channel flow (Poiseuille flow) at depths of ca. 100-230 km (Fig. 2b).

Material in the deeper mantle $(y=300-600 \mathrm{~km})$ moves from the craton edge $(x=\sim 2500 \mathrm{~km})$ towards the craton interior (left side) where it rises to compensate the rightward-moving mass in the channel flow, thus forming large-scale circulation of mantle material. With time, this large-scale, whole-domain circulation shrinks to a convection localized in the right half $(x=2000-4000 \mathrm{~km})$ of the model (Time = 1366 Myr; Fig 2a). The model evolves to form several smaller convection cells with a wavelength of $1000-1500 \mathrm{~km}$ (Time $=2366$ Myr; Fig. 2a).

\subsection{Stage 1: channel flow in the lithosphere}

At Stage 1 (Time = $0-1272$ Myr; Fig. 2b), the channel flow within the lower lithosphere forms two shear zones with high strain rate values. The top shear zone (S1 at a depth of ca. $100-120 \mathrm{~km}$ ) is located beneath the initial TLAB depth at $90 \mathrm{~km}$, whereas the lower shear zone S2 with the maximum strain rate develops roughly at the depth of the cratonic CLAB (at ca. 200-230 km depth, deepening away from the craton edge). The maximum flow velocity is at the mid-point depth (ca. $160-180 \mathrm{~km}$ ) of the 
two shear zones along the profile (Fig. 2b) and forms a parabolic velocity profile typical of a channel flow (Turcotte and Schubert, 2002). This channel flow extends horizontally from the craton interior to the downwelling center at the craton edge and exists in the whole craton over $>2000 \mathrm{~km}$ distance (Fig. 2b). The maximum strain rate and the maximum horizontal displacement rate gradually increase from the craton interior (left side) to the craton edge and the off-craton domain (right side) (Figs. 2b).

The depth profiles of strain rate, material velocity and viscosity within the craton (at distance $x=1190 \mathrm{~km}$ ) illustrate the temporal evolution of the channel flow (Fig. 3). At Stage 1 (<1272 Myr; Fig. 3), the top of the channel flow (S1) drops from a depth of $80 \mathrm{~km}$ (Time $=79 \mathrm{Myr}$ ) to $120 \mathrm{~km}$ (Time $=1272 \mathrm{Myr}$ ) (Fig. 3a). The rate of the channel flow deepening is initially $75 \mathrm{~m} \mathrm{Myr}^{-1}$, so that over the first $400 \mathrm{Myr}$ of the channel flow formation (model time $79 \mathrm{Myr}$ to $495 \mathrm{Myr}$ ) the S1 depth descends by about $30 \mathrm{~km}$. With model evolution, the rate of the channel flow deepening slows down by a factor of 6 (to $12.5 \mathrm{~m} \mathrm{Myr}^{-1}$ ) such that the total deepening is $<10 \mathrm{~km}$ in the following 800 Myr (model time 475 Myr to 1272 Myr). The drop in the channel flow deepening rate is also observed in the velocity and viscosity profiles (Fig. 3b, c).

In the early evolution ( $<79 \mathrm{Myr}$ ), the uppermost layer of the lithosphere ( depth $0-60 \mathrm{~km}$ ) with a viscosity of $10^{25} \mathrm{~Pa}$ s (set as maximum viscosity in the model) acts as a rigid layer (Fig. 3c). In the lower part of the model (depth $>300 \mathrm{~km}$ ), mantle viscosity is $\sim 3$ times higher than in the layer with the channel flow (Figs. $3 b$ and $c$ ). Therefore, the channel flow is surrounded by two rigid layers.

At early Stage 1 (< ca. 200 Myr), geotherms have an intriguing curvature at 200 $\mathrm{km}$ depth (red lines in Fig. 4), when the temperature in the chemical boundary layer is 
higher than in the sublithospheric mantle. This kind of a hot lithospheric geotherm may exist during a period with a very high rate of radioactive heat generation in the Precambrian lithosphere (Michaut and Jaupart, 2007). High temperature of the continental lithosphere root reduces its viscosity and facilitates formation of the channel flow once a sufficient pressure gradient develops in the lithosphere root. This curvature of the geotherm disappears by ca. 475 Myr (Fig. 4), but the channel flow in the lower lithosphere remains (Fig. 3b).

With secular cooling (Fig. 4), the lithosphere overall viscosity increases (Fig. 3c), which reduces channel flow velocity and strain rate. Drippings of a cool asthenosphere material in the right half of the model push hot asthenosphere subhorizontally towards the model edge, causing the asthenosphere material to move passively in the direction opposite to the overlying channel flow (Figs. 2 and 3b). This forms a strong shearing at ca. 180-230 km depth, seen as the channel bottom in our model (Fig. 3b).

\subsection{Stage 2: small-scale convection}

At Stage 2 (model time $>1272 \mathrm{Myr}$ ), multiple small-scale convection cells develop in the sublithospheric upper mantle, and the temperature field in the CBL part of the lithospheric mantle approaches the equilibrium state which lasts for more than $1 \mathrm{Gyr}$ (from 1272 to 2366 Myr; Fig. 4). The transition from Stage 1 to Stage 2 is marked by a leftward migration of convection cells from the right end of the model (Fig. 2b, c). From 1272 Myr to 3066 Myr (Fig. 3a, b), the middle portion of the lithosphere (125 - $175 \mathrm{~km}$ depth) is still subject to a strong shearing, and the velocity and strain rate in the 
sublithospheric mantle sharply increases by $1-2$ orders (Fig. 3a and 3b, note different scales of the upper and bottom panels) as expected for vigorous mantle convection. Note that the flow direction in the bottom part of the lithospheric mantle $(210 \mathrm{~km}-$ $280 \mathrm{~km}$ depth) changes between 1866 Myr and 3066 Myr (Fig. 3b) from the leftward to the rightward, while the channel flow formed at Stage 1 preserves its rightward motion in the lithosphere mantle (ca. $80 \mathrm{~km}-220 \mathrm{~km}$ depth).

\section{Discussion}

\subsection{Conditions for formation of a channel flow}

Continent-scale channel flow is formed in the lower part of Archean chemical lithosphere $(\mathrm{CBL})$ by a horizontal pressure gradient at craton margins. The pressure gradient is caused by downwelling mantle flow formed around the craton-to-noncraton transition due to differences in composition and heat production within the CBL and below it, which were particularly strong in the Archean (Korenaga, 2003).

Maintaining the channel requires the formation of a chemically differentiated continental lithospheric root with density and viscosity lower than in sublithospheric mantle. We ran several test models to examine the roles of compositional density contrast across the $C L A B$ and of asthenosphere viscosity on the formation and evolution of the lithosphere channel flow (Fig. 5). 


\subsubsection{Role OF DENSITY CONTRAST ACROSS THE CLAB}

A continuous channel flow does not form in the absence of a density contrast between the lithospheric and sublithospheric mantle (Model Den0). Instead, multiple convection cells develop (Fig. 5a) and destroy the cratonic lithosphere root.

In contrast, when the density contrast is large $\left(60 \mathrm{~kg} \mathrm{~m}^{-3}\right.$ instead of $\left.20 \mathrm{~kg} \mathrm{~m}^{-3}\right)$, the compositionally light cratonic lithospheric mantle cannot drip into the asthenospheric mantle (Fig. 5b, Model Den60). Reduced dripping results in a higher viscosity of the sublithospheric mantle due to a lower strain rate. This reduces both the intensity of mantle convection and the efficiency of heat diffusion in the sublithospheric mantle. The resulting thermal regime is characterized by cooling of the lithosphere and heating of the deeper upper mantle (Fig. 5b).

\subsubsection{ROLE OF VISCOSITY CONTRAST ACROSS THE CLAB}

Viscosity in the sublithospheric mantle is an important factor for control of mantle dynamics, but it has a complicated dependence on temperature, pressure, stress, volatile content and mineral grain size (Karato, 1995). Chemically depleted dry lithospheric mantle is generally assumed to have a higher viscosity than wet fertile mantle (Peslier et al., 2010), and we test two models with viscosity of the sublithospheric mantle of $1 / 2$ (Model Asthen2) and 1/5 (Model Asthen5) of our model lithospheric mantle viscosity (Fig. 5c, d).

Higher viscosity of the sublithospheric mantle (Model Asten2) reduces the vigor of convection in the sub-lithospheric mantle. In contrast, rigorous convection that efficiently releases heat from the lithosphere to the surface produces an extremely thick thermal lithosphere $(>400 \mathrm{~km})$ in the Asthen5 model. Therefore, the final 
geotherm in the Asthen2 model fits the present cratonic lithosphere geotherms better than the Asthen5 model. In the Asthen5 model, a continuous channel is observed at the early stage of evolution, but mantle temperature decreases without approaching an equilibrium state (Fig. 5d) as observed at Stage 2 of the reference model (Fig. 4).

\subsubsection{Uniqueness of Archean channel flow}

Channel flow cannot form in modern cratonic settings: cold and rigid cratons with high-viscosity lithosphere roots tend to resist the development of a channel flow, even when there is a significant horizontal pressure gradient at the cratonic lithosphere root, e.g., from edge convection. Due to high radioactive heat production in the lithospheric mantle during the Archean, a curved geotherm may have developed in the relatively weak cratonic root (Michaut and Jaupart, 2007).

\subsection{Channel flow and the seismic Mid-Lithosphere Discontinuity}

\subsubsection{Channel Flow AND SEISMic LoW-Velocity zones}

Our numerical model provides a possible dynamic process for the MLD formation by channel flow within the cratonic lithosphere in the Archean. Intensive shearing at the top of the channel flow (layer S1, depth $80-120 \mathrm{~km}$, Fig. 2b, top) produces a low viscosity zone (Fig. 3) at depths consistent with the depth of seismic velocity discontinuities (Thybo and Perchuć, 1997; Rader et al., 2015) (Fig. S1). Although low viscosity does not necessarily require low seismic velocity (Karato, 1995), the seismic low velocity zone is generally regarded as a weaker zone in the upper mantle (Thybo, 2006). Mineral physics experiment on melt-free polycrystalline aggregates of Fo90 olivine indicates that shear modules decrease with reduced grain size ( $\underline{\underline{F u u l} \text { and }}$ 
$\underline{\text { Jackson, 2005). Intensive shearing in the mantle may reduce grain size (Bystricky et al., }}$ 2000), as evidenced by mantle peridotite xenoliths from the Kaapvaal craton with a pronounced drop in olivine grain size from ca. $12 \mathrm{~mm}$ at $120-140 \mathrm{~km}$ depth to $4-8$ $\mathrm{mm}$ below $150 \mathrm{~km}$ depth in the lithospheric mantle (Mercier, 1980). Therefore, shearing-induced grain size reduction may partly result in the formation of a seismic low-velocity zone in the lithosphere.

\subsubsection{Channel flow And mantLe metasomatism}

A global analysis of elastic moduli and densities of mantle xenoliths suggests that hydrous minerals in a chemically distinct mantle layer may also reduce seismic velocity (Rader et al., 2015). Volatile-rich melts percolating through the lower lithosphere may accumulate at ca. $80 \mathrm{~km}$ depth, leading to accumulations of minerals with low seismic velocities (pyroxenes, phlogopite, amphibole, carbonates) (Aulbach et al., 2017). The presence of these minerals at mid-lithosphere depths was proposed as an explanation of seismic MLD observed in S-RFs (Selway et al., 2015). Besides, fluid accumulation affects peridotite solidus, such that the mid-lithosphere seismic discontinuity may be explained by a seismic wave speed reduction where temperatures are close to the wet solidus (Thybo, 2006).

The upper shear zone with horizontal deformation caused by the channel flow may cause anisotropy of permeability and therefore change the flow direction of rising melt to (sub)horizontal (Morgan, 1987) (Fig. 6). In case of melt segregation, the layer above the melt zone with a temperature lower than the solidus functions as an impermeable cap and the contraction in the freezing zone may form a porous layer beneath which lateral migration of melt may take place (Sparks and Parmentier, 1991). 
For simplicity, our model does not include these complex processes, but channel flow in the lower lithosphere can accumulate molten material at its top (Fig. 6).

Former presence of melts at a depth of $80-100 \mathrm{~km}$ in the lithosphere is supported by seismic normal-incidence reflection profiles from several locations. These profiles image strong horizontal reflections generally around $24 \mathrm{~s}$ two-way time (Steer et al., 1998), e.g. in northern Europe in the Skagerrak (Lie et al., 1990) and the North sea (Mona Lisa Working Group, 1997) areas, and in the Urals region (Knapp et al., 1996). These observations are consistent with the presence of magmatic sills in the depth range of $80-100 \mathrm{~km}$, where they may have been emplaced following mantle peridotite melting in the presence of carbon dioxide and water (Thybo, 2006).

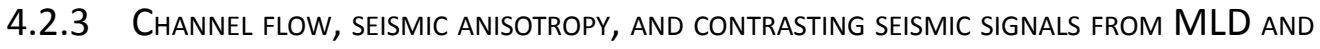

\section{$\mathrm{LAB}$}

Strong radial anisotropy, which is stronger in the shallow mid-lithosphere mantle

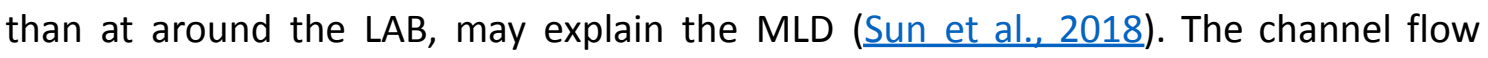
should cause strong radial anisotropy at the top (S1) and the base (S2) of the channel (especially for non-Newtonian material) (Fig. 2b, top), but not in the central part of the channel, which has a very low strain rate typical of the Poiseuille flow. Radial anisotropy may produce a seismic MLD as observed in S-RF (Selway et al., 2015), although it may not lead to seismic velocity reduction.

Understanding the evolution of thermal lithosphere in relation to the TLAB may advance our understanding of seismic anisotropy in the upper mantle. Our numerical models predict two stages with two distinct mantle material motion patterns (Fig. 2, 6). A continuous channel flow forms beneath the TLAB at Stage 1, while multiple small 
convection cells underlie the TLAB at Stage 2 . Therefore, at stage 1 , a constant horizontal shear atop the TLAB due to the channel flow should produce a stronger radial anisotropy than at Stage 2 , which is characterized by alternating mantle up- and down-wellings.

Therefore, a shallow MLD may be associated with frozen-in anisotropy from a continuous channel flow in an ancient asthenosphere. Its preservation requires cooling of the shallow mantle to a critical temperature of $900{ }^{\circ} \mathrm{C}$ (Fig. 3d): at higher temperature, the mobility of olivine crystals is too high to preserve the anisotropy since the Precambrian (Goetze and Kohlstedt, 1973).

After billions of years of evolution, the CLAB, formed by mantle differentiation on the early Earth, is no longer flat as in the initial model setup (Fig. 2a, 6). Instead, a wave-like topography with short wavelength "V"-shaped chemical layer drippings is created by multiple convection cells. These drippings move material from the chemical lithosphere into the convecting sublithospheric mantle, leading to an intensive mixing of the lower portion of the chemical lithosphere with the underlying mantle. The downward smearing of the chemical lithosphere, as well as metasomatism caused by the upward percolation of volatiles and basaltic melts within the cratonic lithosphere, may create a transitional chemical boundary layer in the lower portion of the lithospheric root, as observed in mantle xenoliths from various cratons (Griffin et al., 2003). This may explain the difficulties with detecting the transitional CLAB by seismic tomography and receiver function studies (Rychert and Shearer, 2009). 


\subsection{Implications for mantle dynamics and stability of cratons}

The channel flow model may, intuitively, seem to be in conflict with the

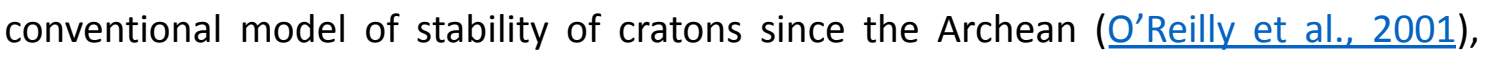
which is not the case. At early stages of the channel flow, the TLAB is shallower than the CLAB, and after about 500 Myr the chemical lithosphere cools to a temperature below the hydrous solidus (a case with 400 ppm water; Fig. 4). At this time, a very low flow speed in the channel (as low as $0.005 \mathrm{~cm} \mathrm{yr}^{-1}$ ) may, at maximum, lead to a $50 \mathrm{~km}$ material displacement over 1 Gyr. Such scale of displacement in a continent root is much slower than plate velocities. Although at Stage 2 the rate of horizontal material displacement increases by one order of magnitude (Fig. 3b, bottom), the largest velocity of the material flow occurs below the CLAB (depth $>200-250 \mathrm{~km}$ ) rather than within the cratonic lithosphere. Additionally, migration of convection cells causes material of the cratonic root to move back and forth within the underlying convection cells, unlike Stage 1 when material flows only in one direction (Fig. 3b, top). Therefore, the final cumulative offset between the crust and the cratonic lithosphere root may not be reflected in mantle xenoliths.

Physically, the channel flow may form only when cratonic lithosphere is significantly warmer than at present. In our numerical model, we assume that this thermal condition is satisfied in the Archean, with mantle temperatures ca. $200{ }^{\circ} \mathrm{C}$ higher than at present. However, large-scale mantle thermal anomalies, like plumes, may impart heat at the base of cratons such that it may increase temperature at the lithosphere base by $100-150{ }^{\circ} \mathrm{C}$, possibly out to distances of $500 \mathrm{~km}$ from the impact center (Sleep, 2003). In such cases, channel flow may also be triggered in the lower 
cratonic lithosphere if the basal temperature increases by thermal events from below. This may contribute to explaining some enigmatic features, such as high (2-7\%) shear wave velocity anomalies which appear to continue from the ancient continental cratonic roots of the southern African cratons to beneath the oceanic basins $500-1300$ $\mathrm{km}$ away from the cratonic margin (Grand, 2002). If mantle thermal anomaly associated with the separation of the South American and African continents increased the temperature of the cratonic root by $100-150^{\circ} \mathrm{C}$, it would have reduced the mantle viscosity by approximately two orders of magnitude. Both rifting and mantle edge convection tend to create a low-pressure zone at cratonic margins with respect to cratonic interior, thus attracting a weakened cratonic root to flow towards an ocean basin, similar to the pattern observed at stage 1 (Fig. 2). If the continental plate moves in the direction opposite to the channel flow, it may enhance shearing at depths of the top of the channel flow ( $\mathrm{S} 1$ in Fig. $2 \mathrm{~b}$ ), and this process may explain seismic observations around the southern Africa (Wang et al., 2017).

\section{Conclusions}

With a two-dimensional numerical geodynamical model, we examine how the secular cooling down of a chemical lithosphere affects the thermomechanical evolution of a craton. With a shallower TLAB than the CLAB and a step-like transition in lithospheric mantle thickness as a priori, the numerical experiments show different flow patterns beneath the TLAB (Fig. 6).

(1) A continent-scale channel flow (Stage1) is formed in lower chemical lithosphere due to horizontal pressure gradient, which is triggered by negative Rayleigh-Taylor 
instabilities happened around the chemical lithosphere transitional zone. Formation of a channel flow in Stage1 may happen in the Archean Earth which is supposed to be much hotter than the present state. The intensively sheared roof of a channel may reduce olivine grain size, accumulate contemporary volatile-rich melt rising from below and create frozen-in radial anisotropy of seismic waves. All these factors contribute to the development of a discontinuity in seismic-wave velocity.

(2) With temperature cooling down in the chemical lithosphere, but sufficient internal heating in the sublithospheric mantle, the flow structure beneath the TLAB changes to be smaller multiple convection cells (Stage2) with a wavelength of approximately thousand kilometers. This multiple convection cells with alternative upwelling and downwelling flow may reduce radial anisotropy strength with respect to that caused by a continuous channel flow in the shallower lithosphere. The downwelling entraining chemical lithosphere material into and mixing with the deeper mantle may cause a transitional boundary in composition. This transitional chemical boundary is thus hard to be detected by seismic-wave tomography and receiver function studies.

\section{Acknowledgements}

The code we used here was mainly developed by Dr. Zurab Chemia. HY was supported by the Melbourne Research Scholarship. IMA and HT are partially supported by the MOST special funds of China for GPMR State Key Laboratory (GPMR2019010). 
a

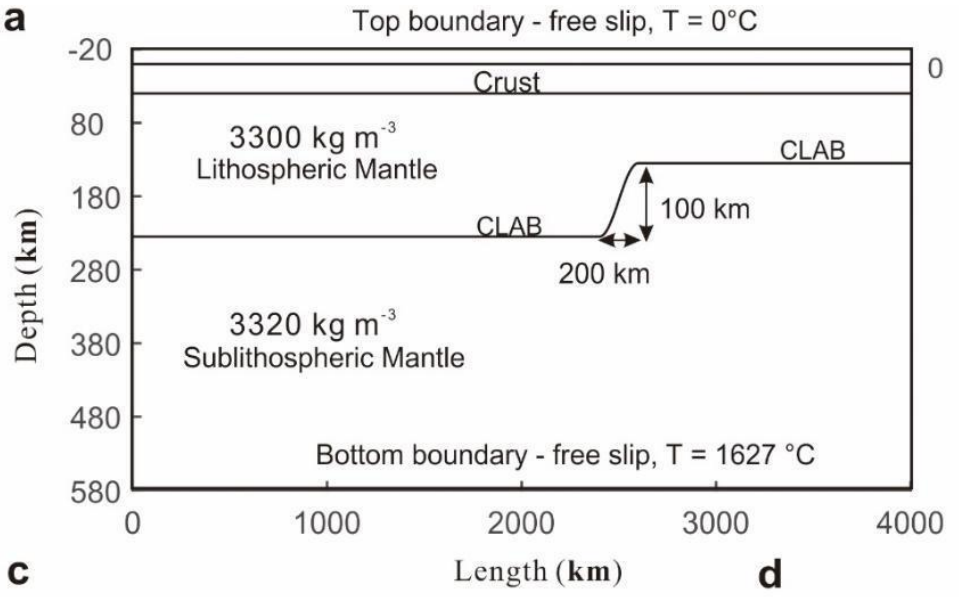

b

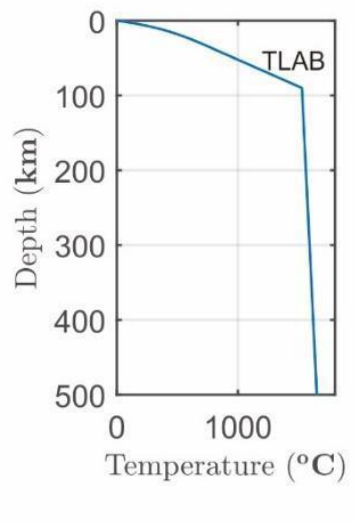

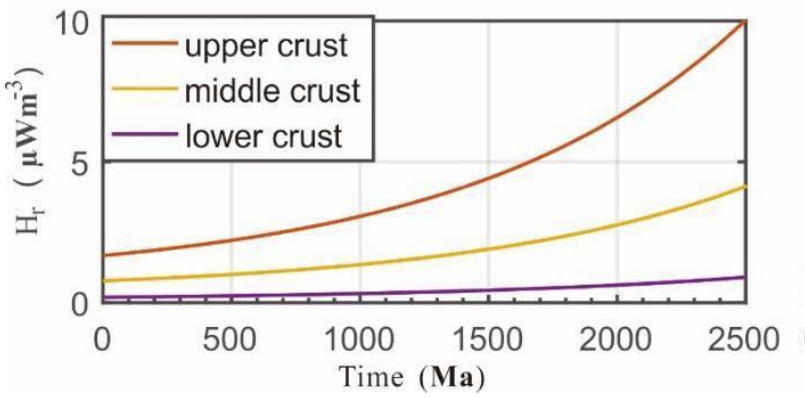

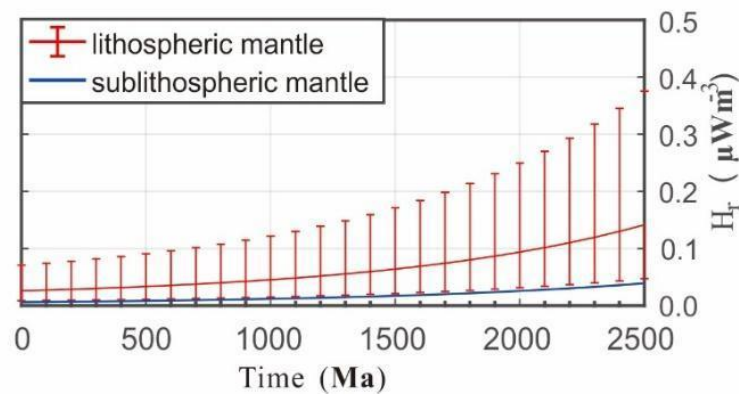

Figure 1. Initial model setup for 2D numerical experiments.

(a) The model top $20 \mathrm{~km}$ is made of a low-viscosity layer, and the surface $\mathrm{y}=0$ refers to the topography, not to the model top. The underlying crust includes three layers (upper, middle and lower crust) with thicknesses of $10 \mathrm{~km}, 15 \mathrm{~km}$ and $15 \mathrm{~km}$, respectively. The CLAB (chemical $L A B$ ) is at a depth of $235 \mathrm{~km}(x=0-2400 \mathrm{~km})$ and 135 $\mathrm{km}(x=2600-4000 \mathrm{~km})$, with a linear transition $(x=2400-2600 \mathrm{~km})$ between the two domains.

(b) Initial 1D temperature field set to be hotter in Archean cratonic than present lithosphere (Turcotte and Schubert 2002): $T=T_{0}+\frac{q_{m} y}{k}+\frac{\left(q_{0}-q_{m}\right) h_{r}}{k}\left(1-e^{-\frac{y}{h_{r}}}\right)$, where $T_{0}$ is surface temperature, $q_{0}=120 \mathrm{~mW} \mathrm{~m}^{-2}$ - initial surface heat flow (double of the present continental average due to higher Archean heat generation), $q_{m}=35 \mathrm{~mW}$ $\mathrm{m}^{-2}$ - heat flow from the mantle (set up at the upper limit of observations in present cratonic mantle, (Artemieva and Mooney, 2001)); $h_{r}=10 \mathrm{~km}$ - characteristic depth of radioactive heat generation, and $k=2.7 \mathrm{~mW} \mathrm{~m}^{-2}$ - thermal conductivity in the crust. Temperature linearly increases from the Moho depth $(40 \mathrm{~km})$ to the thermal LAB (TLAB) with $1500{ }^{\circ} \mathrm{C}$ at $90 \mathrm{~km}$ depth at time zero (Archean), and then follows the adiabatic mantle gradient of $0.3^{\circ} \mathrm{C} \mathrm{km}^{-1}$.

(c, d) Change of radioactive heat generation decay with time (zero corresponds to the present time) in three crustal layers (c) and two mantle layers (d) (based on Huang et al., 2013). The model start time corresponds to the Precambrian Earth, and the values at $1700 \mathrm{Ma}$ are selected as the starting points for the forward modelling. Red vertical bars in (d) shows the possible ranges of radioactive heat generation in the lithospheric mantle, for which we take the upper limit of the heat generation. 

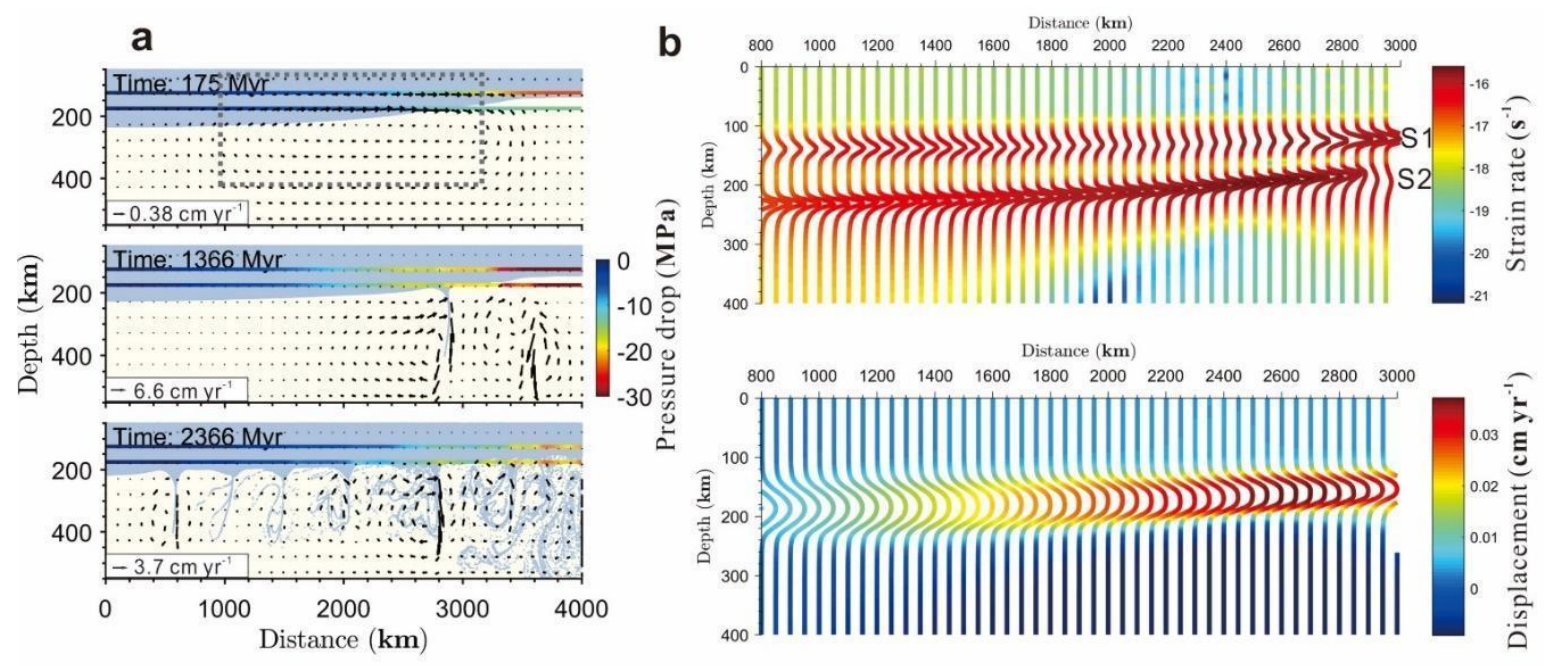

Figure 2. (a) Snapshots of the model evolution after 175, 1366 and 2366 Myr respectively.

Gray shading - chemical lithosphere; pale yellow - asthenospheric mantle. Black arrows show velocity of material motion. Two color lines at depths of $125 \mathrm{~km}$ and 175 $\mathrm{km}$ show pressure drop with respect to pressure at the leftmost point at the corresponding depth. Density inversion at the craton edge around $x=2500 \mathrm{~km}$ produces a low pressure zone to the right which drives a rheologically weak material due to high temperature in the chemical lithosphere root towards region with a thinner lithosphere, thus forming a continuous channel flow of few thousands kilometers long. At 1366 Myr, the flow begins to split into multiple smaller convection cells (Stage 1). The downwelling flow of the chemical lithospheric material mixes it with a deeper mantle (model time 2366 Myr, Stage 2).

(b) Strain rate (top) and horizontal displacement traces (bottom) after $175 \mathrm{Myr}$ along $x=800-3000 \mathrm{~km}$ (area within the box in (a, top)) sampled with $50 \mathrm{~km}$ distance step. Changes in the parameters are shown by both colors and offsets from the vertical. Each offset of the trace is scaled to the maximum amplitude with color showing the absolute value. Deformation of the lower lithospheric mantle is localized in two shear zones (S1 and S2, top image) at ca. 100-230 km depth. The parabolic velocity profile is symmetric about the centerline and is rightwards channeled due to the pressure gradient (a). 

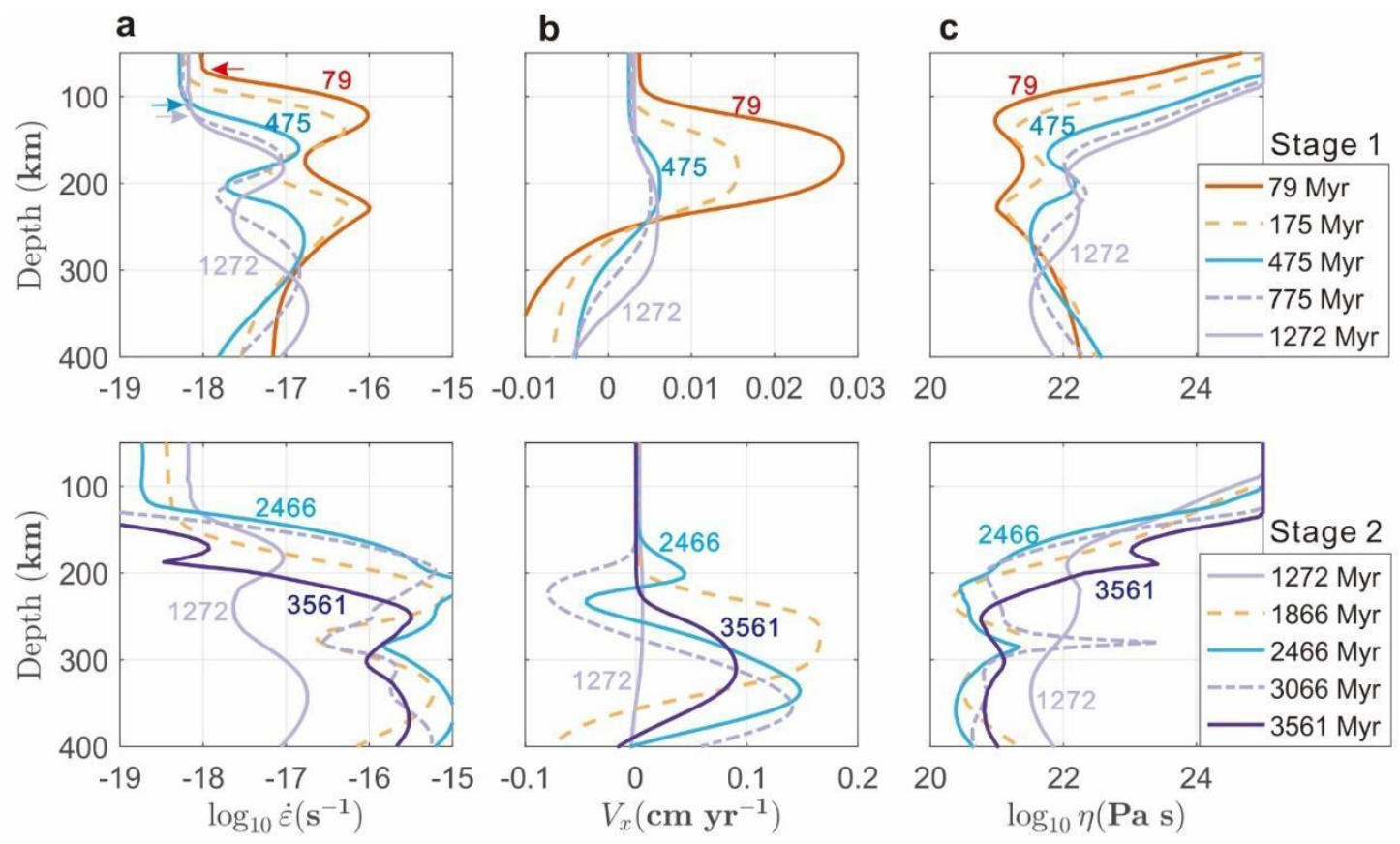

Figure 3. Depth profiles for model evolution at $x=1190 \mathrm{~km}$ for model time from 79 Myr (Stage 1) to $3561 \mathrm{Myr}$ (Stage 2) for strain rate (a), horizontal material velocity (b), effective viscosity (c). Upper panels - Stage 1 with large-scale channel flow in the lower lithosphere; lower panels - Stage 2 with multiple convection cells formed in the asthenosphere. Arrows in (a) mark the top of the channel flow at different time at Stage 1. 


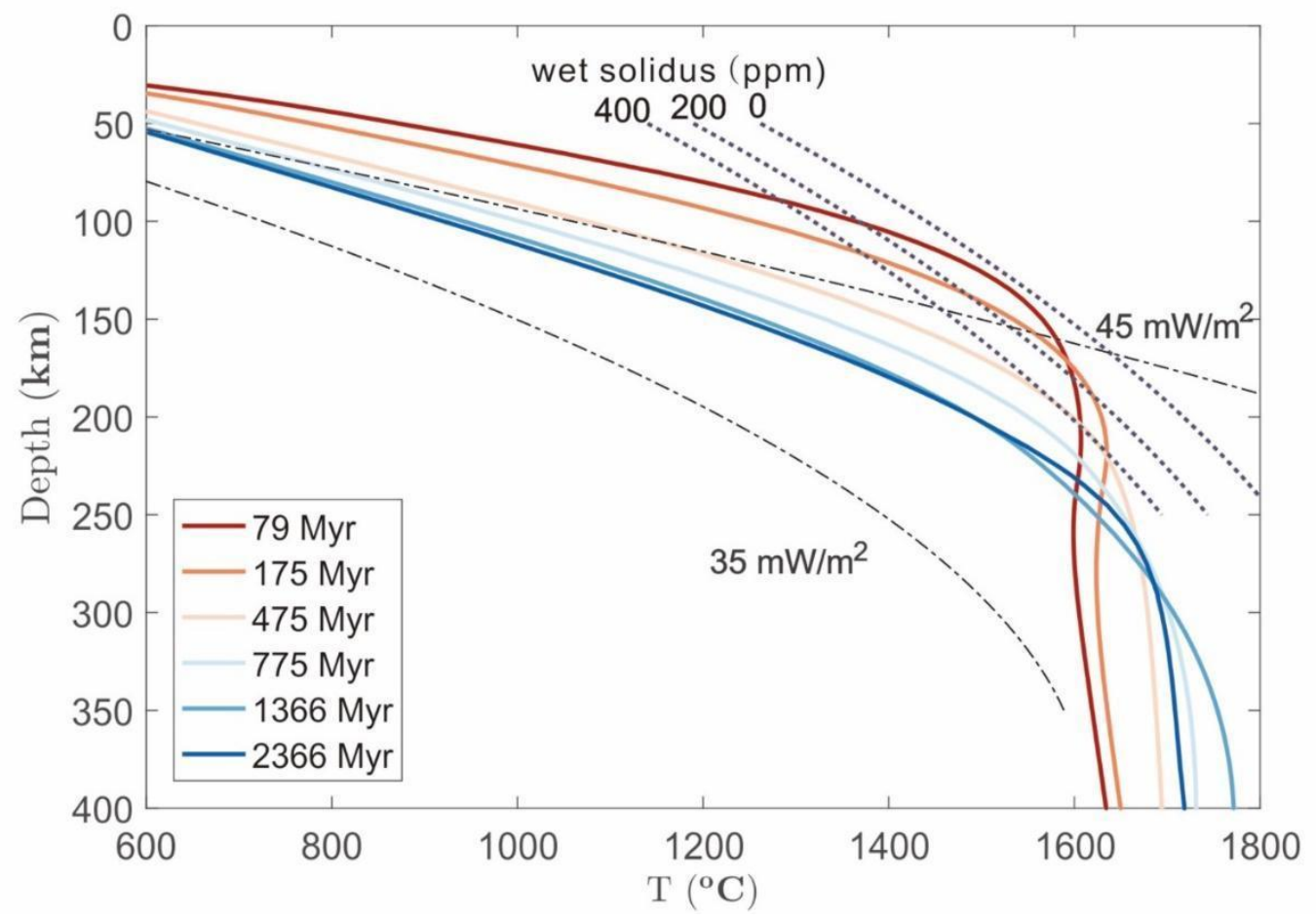

Figure 4. Depth profiles for temperature evolution at $x=1190 \mathrm{~km}$ for model times 79 Myr (Stage 1) to $2366 \mathrm{Myr}$ (Stage 2). Temperature evolution shows a fast-cooling rate in the lithospheric mantle at Stage 1 (red lines), and approaches the equilibrium state at Stage 2 (blue lines). Three dotted lines show dry and wet peridotite solidus with 0, 200 and 400 ppm water content (Katz et al., 2003). Black dash-dot lines are typical continental geotherms for surface heat flow of 35 and $45 \mathrm{~mW} \mathrm{~m}^{-2}$ (Turcotte and Schubert 2002). 


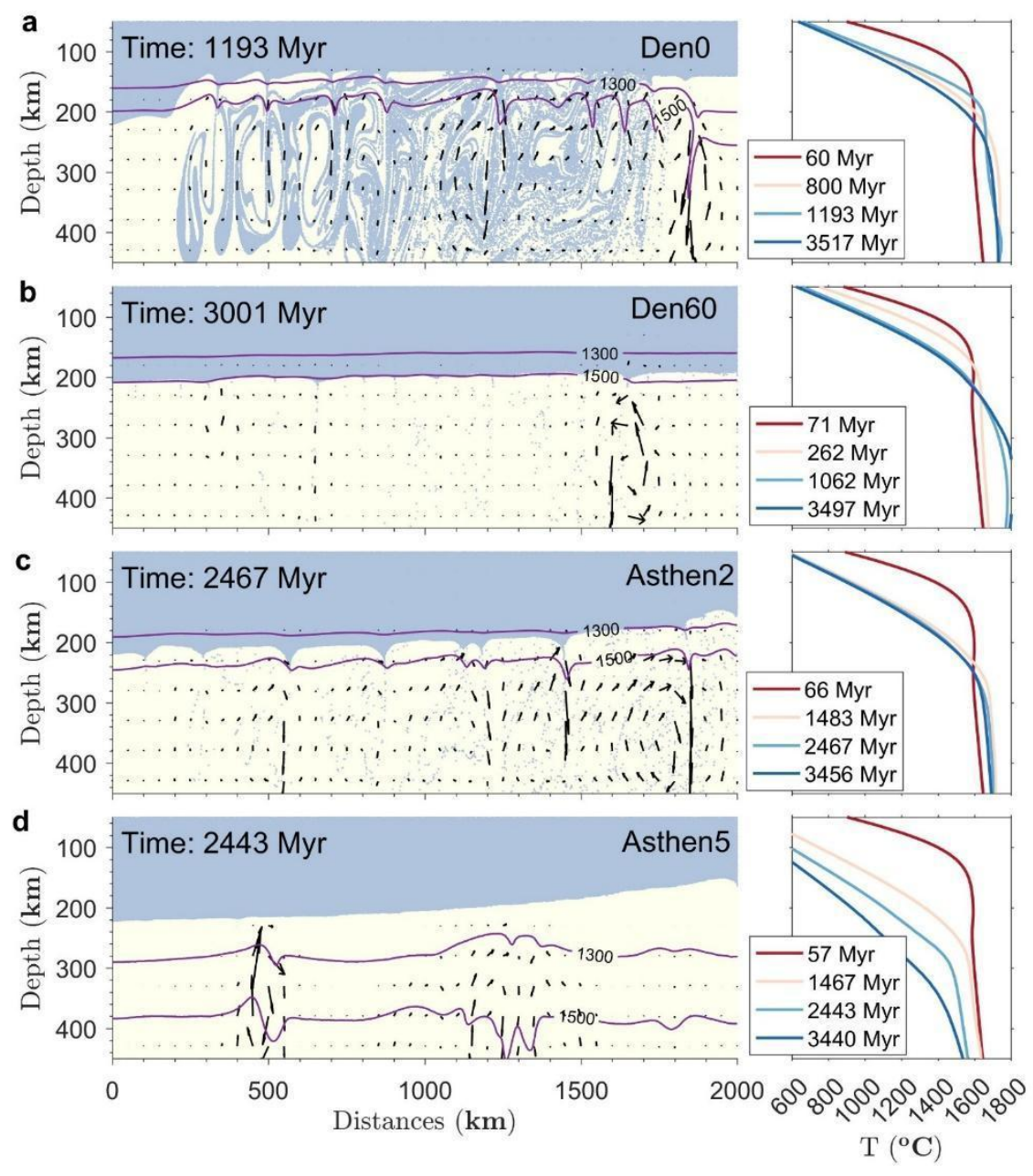

Figure 5. Numerical solutions for contrasting mantle evolutions. On the left - snapshots of models with different evolution styles. The two purple lines are isotherms of $1300{ }^{\circ} \mathrm{C}$ and $1500^{\circ} \mathrm{C}$. On the right - the corresponding geotherms at model distance $x=1190$ $\mathrm{km}$ at four model times. The models are compared with the reference model (Figs. 1-4).

(a) The model Den0 has no density contrast between the chemical lithospheric mantle $(\mathrm{CBL})$ and the sublithospheric mantle. Lower buoyancy of the $\mathrm{CBL}$ due to lower temperature than in the sublithospheric mantle involves the continental material into convection and produces multiple small-scale convection cells.

(b) The model Den60 has a high-density contrast of $60 \mathrm{~kg} \mathrm{~m}^{-3}$ apt to protect the cratonic lithosphere root from being disrupted by mantle convection. The entrainment of the chemical lithosphere into the sublithospheric mantle convection is reduced due to high lithospheric mantle buoyancy at stage 2 . It reduces the vigor of mantle convection and reduces the efficiency of radiogenic heat release, thus increasing temperature in a deeper part of the convective upper mantle.

(c-d) The models Asthen2 (c) and Asthen5 (d) have reduced viscosity in the sublithospheric mantle equal to $1 / 2$ and $1 / 5$ of the reference model, respectively. As a 
result, mantle convection becomes more rigorous, and the efficiency of the release of radioactive heat increases. A fast cooling of a deeper upper mantle leads to an extremely thick lithospheric mantle in the Asthen 5 model. 


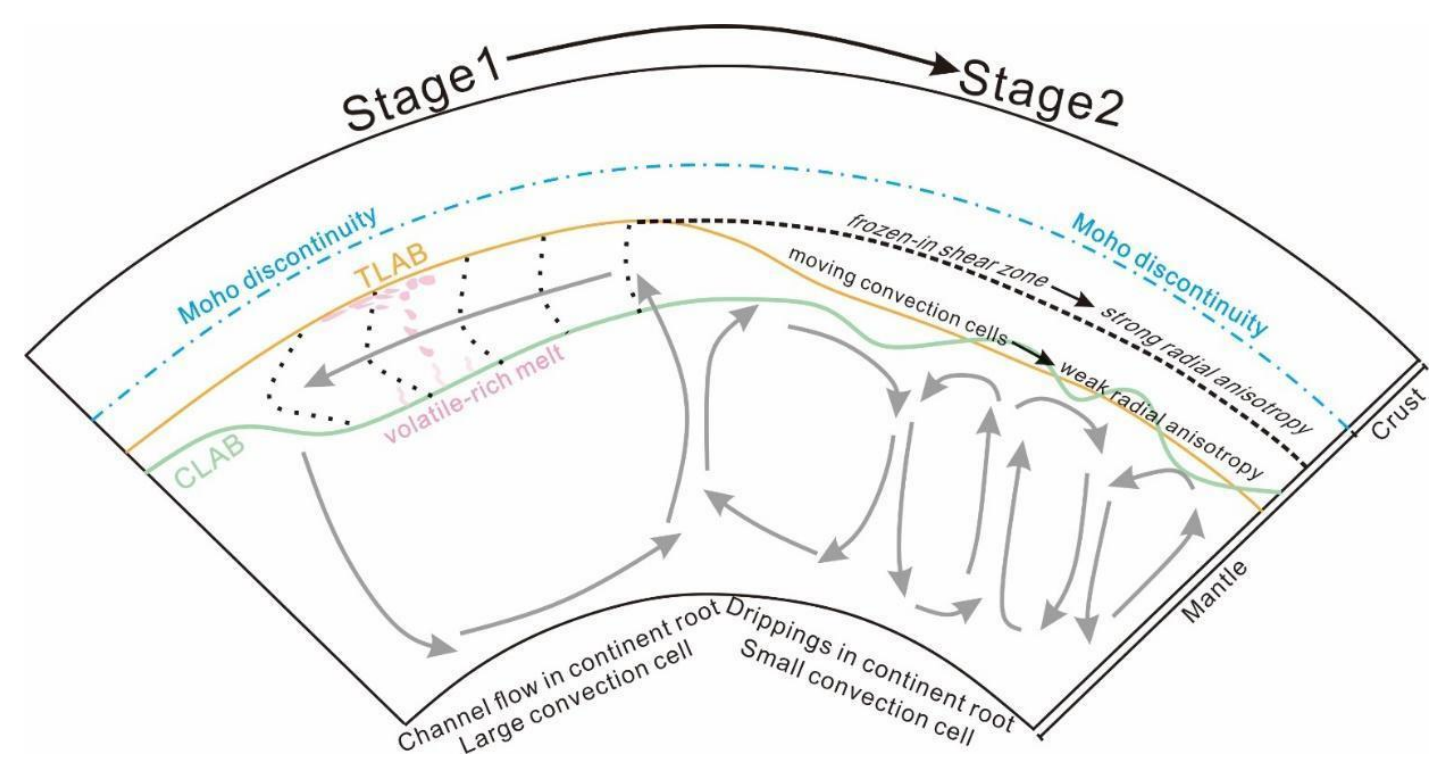

Figure 6. A sketch illustrating mantle evolution at different stages. It shows how footprints of the once existing channel flow structure remain preserved in the present mid-lithospheric mantle.

\section{References}

Abramovitz, T., Thybo, H., Perchuc, E., 2002. Tomographic inversion of seismic Pand S-wave velocities from the Baltic Shield based on FENNOLORA data. Tectonophysics 358, 151-174.

Artemieva, I.M., Mooney, W.D., 2001. Thermal thickness and evolution of Precambrian lithosphere: A global study. J Geophys Res-Sol Ea 106, 16387-16414.

Aulbach, S., Massuyeau, M., Gaillard, F., 2017. Origins of cratonic mantle discontinuities: A view from petrology, geochemistry and thermodynamic models. Lithos 268, 364-382.

Bystricky, M., Kunze, K., Burlini, L., Burg, J.-P., 2000. High Shear Strain of Olivine Aggregates: Rheological and Seismic Consequences. Science 290, 1564-1567.

Carlson, R.W., Pearson, D.G., James, D.E., 2005. Physical, chemical, and chronological characteristics of continental mantle. Reviews of Geophysics 43.

Chen, C., Gilbert, H., Fischer, K.M., Andronicos, C.L., Pavlis, G.L., Hamburger, M.W., Marshak, S., Larson, T., Yang, X., 2018. Lithospheric discontinuities beneath the US Midcontinent-signatures of Proterozoic terrane accretion and failed rifting. Earth and Planetary Science Letters 481, 223-235.

Dickin, A.P., Halliday, A.N., 1995. Radiogenic Isotope Geology. Economic Geology and the Bulletin of the Society of Economic Geologists 90, 2099-2099.

Egorkin, A.V., Zuganov, S.K., Pavlenkova, N.A., Chernyshev, N.M., 1987. Results of Lithospheric Studies from Long-Range Profiles in Siberia. Tectonophysics 140, 29-47.

Faul, U.H., Jackson, I., 2005. The seismological signature of temperature and grain size variations in the upper mantle. Earth and Planetary Science Letters 234, 119-134. 
Goetze, C., Kohlstedt, D., 1973. Laboratory study of dislocation climb and diffusion in olivine. Journal of Geophysical Research 78, 5961-5971.

Grand, S.P., 2002. Mantle shear-wave tomography and the fate of subducted slabs. Philosophical Transactions of the Royal Society of London. Series A: Mathematical, Physical and Engineering Sciences 360, 2475-2491.

Griffin, W.L., O'Reilly, S.Y., Natapov, L.M., Ryan, C.G., 2003. The evolution of lithospheric mantle beneath the Kalahari Craton and its margins. Lithos 71, 215-241.

Gung, Y., Panning, M., Romanowicz, B., 2003. Global anisotropy and the thickness of continents. Nature 422, 707-711.

Herzberg, C., Condie, K., Korenaga, J., 2010. Thermal history of the Earth and its petrological expression. Earth and Planetary Science Letters 292, 79-88.

Huang, Y., Chubakov, V., Mantovani, F., Rudnick, R.L., McDonough, W.F., 2013. A reference Earth model for the heat-producing elements and associated geoneutrino flux. Geochem Geophy Geosy 14, 2003-2029.

Jones, A.G., Lezaeta, P., Ferguson, I.J., Chave, A.D., Evans, R.L., Garcia, X., Spratt, J., 2003. The electrical structure of the Slave craton. Lithos 71, 505-527.

Karato, S., 1995. Effects of Water on Seismic-Wave Velocities in the Upper-Mantle. P Jpn Acad B-Phys 71, 61-66.

Karato, S.I., Olugboji, T., Park, J., 2015. Mechanisms and geologic significance of the mid-lithosphere discontinuity in the continents. Nature Geoscience 8, 509-514.

Katz, R.F., Spiegelman, M., Langmuir, C.H., 2003. A new parameterization of hydrous mantle melting. Geochem Geophy Geosy 4.

Knapp, J.H., Steer, D.N., Brown, L.D., Berzin, R., Suleimanov, A., Stiller, M., Luschen, E., Brown, D.L., Bulgakov, R., Kashubin, S.N., Rybalka, A.V., 1996. Lithosphere-scale seismic image of the southern Urals from explosion-source reflection profiling. Science 274, 226-228.

Kopylova, M.G., Caro, G., 2004. Mantle xenoliths from the Southeastern Slave craton: Evidence for chemical zonation in a thick, cold lithosphere. Journal of Petrology 45, 1045-1067.

Kopylova, M.G., Russell, J.K., 2000. Chemical stratification of cratonic lithosphere: constraints from the Northern Slave craton, Canada. Earth and Planetary Science Letters 181, 71-87.

Korenaga, J., 2003. Energetics of mantle convection and the fate of fossil heat. Geophysical Research Letters 30.

Lee, C.T.A., Lenardic, A., Cooper, C.M., Niu, F.L., Levander, A., 2005. The role of chemical boundary layers in regulating the thickness of continental and oceanic thermal boundary layers. Earth Planetary Science Letters

230, 379-395.

Lie, J.E., Pedersen, T., Husebye, E.S., 1990. Observations of Seismic Reflectors in the Lower Lithosphere beneath the Skagerrak. Nature 346, 165-168.

Mareschal, M., Kellett, R.L., Kurtz, R.D., Ludden, J.N., Ji, S., Bailey, R.C., 1995. Archaean cratonic roots, mantle shear zones and deep electrical anisotropy. Nature 375, 134-137.

Mercier, J.C.C., 1980. Magnitude of the Continental Lithospheric Stresses Inferred from Rheomorphic Petrology. Journal of Geophysical Research 85, 6293-6303. 
Michaut, C., Jaupart, C., 2007. Secular cooling and thermal structure of continental lithosphere. Earth and Planetary Science Letters 257, 83-96.

Mona Lisa Working Group, 1997. MONA LISA-Deep seismic investigations of the lithosphere in the southeastern North Sea. Tectonophysics 269, 1-19.

Morgan, J.P., 1987. Melt migration beneath mid-ocean spreading centers. Geophysical Research Letters 14, 1238-1241.

Nisbet, E.G., Cheadle, M.J., Arndt, N.T., Bickle, M.J., 1993. Constraining the potential temperature of the Archaean mantle: a review of the evidence from komatiites. Lithos 30, 291-307.

O'Reilly, S.Y., Griffin, W.L., Poudjom Djomani, Y.H., Morgan, P., 2001. Are lithospheres forever. Tracking changes in subcontinental lithospheric mantle through time: GSA Today 11, 4-10.

Perchuc, E., Thybo, H., 1996. A new model of upper mantle P-wave velocity below the Baltic Shield: Indication of partial melt in the 95 to $160 \mathrm{~km}$ depth range. Tectonophysics 253, 227-245.

Peslier, A.H., Woodland, A.B., Bell, D.R., Lazarov, M., 2010. Olivine water contents in the continental lithosphere and the longevity of cratons. Nature 467, 78-81.

Rader, E., Emry, E., Schmerr, N., Frost, D., Cheng, C., Menard, J., Yu, C.Q., Geist, D., 2015. Characterization and Petrological Constraints of the Midlithospheric Discontinuity. Geochem Geophy Geosy 16, 3484-3504.

Rybach, L., 1976. Radioactive Heat-Production in Rocks and Its Relation to Other Petrophysical Parameters. Pure and Applied Geophysics 114, 309-317.

Rychert, C.A., Shearer, P.M., 2009. A global view of the lithosphere-asthenosphere boundary. Science 324, 495-498.

Savage, B., Silver, P.G., 2008. Evidence for a compositional boundary within the lithospheric mantle beneath the Kalahari craton from $\mathrm{S}$ receiver functions. Earth and Planetary Science Letters 272, 600-609.

Selway, K., Ford, H., Kelemen, P., 2015. The seismic mid-lithosphere discontinuity. Earth and Planetary Science Letters 414, 45-57.

Sleep, N.H., 2003. Geodynamic implications of xenolith geotherms. Geochem Geophy Geosy 4.

Sparks, D.W., Parmentier, E.M., 1991. Melt Extraction from the Mantle beneath Spreading Centers. Earth and Planetary Science Letters 105, 368-377.

Steer, D.N., Knapp, J.H., Brown, L.D., 1998. Super-deep reflection profiling: Exploring the continental mantle lid. Tectonophysics 286, 111-121.

Sun, W., Fu, L.Y., Saygin, E., Zhao, L., 2018. Insights Into Layering in the Cratonic Lithosphere Beneath Western Australia. Journal of Geophysical Research: Solid Earth.

Thybo, H., 2006. The heterogeneous upper mantle low velocity zone. Tectonophysics 416, 53-79.

Thybo, H., Perchuć, E., 1997. The Seismic $8^{\circ}$ Discontinuity and Partial Melting in Continental Mantle. Science 275, 1626-1629.

Turcotte, D., Schubert, G., 2002. Geodynamics, 472 pp.

Wang, Z.S., Kusky, T.M., Capitanio, F.A., 2017. Ancient Continental Lithosphere Dislocated Beneath Ocean Basins Along the Mid-Lithosphere Discontinuity: A Hypothesis. Geophysical Research Letters 44, 9253-9260. 
Yang, H., Chemia, Z., Artemieva, I.M., Thybo, H., 2018. Control on off-rift magmatism: A case study of the Baikal Rift Zone. Earth and Planetary Science Letters 482, 501-509.

Yuan, H., Romanowicz, B., 2010. Lithospheric layering in the North American craton. Nature 466, 1063-1068. 